\title{
Expression of ras p21 in benign and malignant thyroid lesions
}

\author{
S. TSELENI-BALAFOUTA ${ }^{1}$, E.S. GONOS ${ }^{2}$ and D.A. SPANDIDOS ${ }^{2,3}$ \\ ${ }^{1}$ Department of Pathology, Medical School, University of Athens, Athens; ${ }^{2}$ Institute of Biological Research and Biotechnology, \\ National Hellenic Research Foundation, Athens; ${ }^{3}$ Medical School, University of Crete, Heraklion, Crete, Greece
}

Received June 21, 1993; Accepted August 18, 1993

\begin{abstract}
It is now widely accepted that human neoplasms arise as a result of a sequence of mutations affecting the structure of genes involved in growth control. Identifying the nature of such genetic mutations in thyroid neoplasms and their prevalence in the various tumor phenotypes is critical to the understanding of their pathogenesis. Mutational activation of ras oncogenes has been associated with human thyroid neoplasia. We examined the expression of ras oncogene in benign hyperplastic or inflamatory lesions of the goiter, as well as in benign and malignant thyroid tumors. Although no significant differences of ras oncogene expression was found between benign and malignant lesions, the overexpression in proliferative areas generally suggests the possible involvement of ras oncogene in the trophic hormone control of the thyroid.
\end{abstract}

\section{Introduction}

Proto-oncogenes are thought to have regulatory roles in normal cell proliferation and differentiation $(1,2)$. They may contribute to the development and/or maintenance of the malignant phenotype, when there is an alteration of their function. They are overexpressed in a wide variety of human cancers (3). In some cases tumor aggressivity and state of differentiation have been correlated to the expression of certain oncogenes (3).

The study of oncogene expression in the thyroid gland could be of particular interest, due to the existence of a wide range of both hyperplastic and neoplastic growth abnormalities, which are very common and are often subjected to surgical removal. ras oncogenes in particular have been found to be activated by qualitative (4) or quantitative (5-7) changes.

In this study we report data on the expression of rasoncogene in benign hyperplastic or inflammatory lesions of the goiter in benign and malignant thyroid tumors. Our data show no significant differences in the expression of ras-

Correspondence to: Professor DA Spandidos, Institute of Biological Research and Biotechnology, National Hellenic Research Foundation, 48 Vas. Constantinou Avenue, Athens 116 35, Greece

Key words: RAS oncoprotein, thyroid lesions oncogene between benign and malignant lesions. The overexpression in proliferative areas generally suggests the possible involvement of ras-oncogene in the trophic hormone control of the thyroid.

\section{Materials and methods}

The study was based on 66 cases of both benign and malignant conditions of thyroid. The tissue samples were collected from surgically removed thyroid lobes of patients subjected to either partial or total thyroidectomy. The cases included 16 nodular goiters (10 were of 'parenchymatous' type whereas the other 6 were of architecturally macrofollicular 'colloid' type), 2 cases of Grave's disease, 4 cases of Hashimoto's thyroiditis, 5 follicular adenomas and 39 cases of thyroid cancer and the following types of carcinomas: 23 papillary, 7 follicular, 8 medullary and 1 anaplastic. In 26 cases of thyroid the non-tumorous parenchyma appeared normal whereas in the 13 remaining tumors changes of lymphocytic thyroiditis of varying degree were demonstrable in the non-tumorous tissue.

The histological diagnosis was based on sections stained with $\mathrm{H}$ and $\mathrm{E}$. The expression of $\mathrm{H}$-ras-oncogene was studied on formalin-fixed and paraffin-embedded tissue sections by detection of ras p 21 protein with the use of a 3-step immunoperoxidase technique as previously described (5). Paraffin sections were mounted on slides, incubated at $60^{\circ} \mathrm{C}$ for 24 hours and deparaffinized in xylene. The expression of the H-ras oncogene was examined in the sections of all cases with benign and malignant lesions as well as in the 'normal' parenchyma observed in the vicinity of thyroid tumors. The staining pattern was graded as negative or equivocal $( \pm)$, moderate $(+)$ or intense $(++)$.

\section{Results}

The expression of H-ras oncogene was demonstrable by diffuse cytoplasmic immunoreactivity for ras p21 in the epithelial follicular cells or in the carcinomatous cells focally or in all regions of the examined tissue (Fig. 1). The nontumorous parenchyma adjacent to follicular adenomas and to follicular and papillary carcinomas having normofollicular structure without any infiltration by inflammatory cells showed little or no reactivity for ras p21 (Fig. 2). The staining in the non-tumorous thyroid tissue by the presence of medullary carcinoma was more intense than by the presence of follicle cell-carcinomas. All cases of nodular 


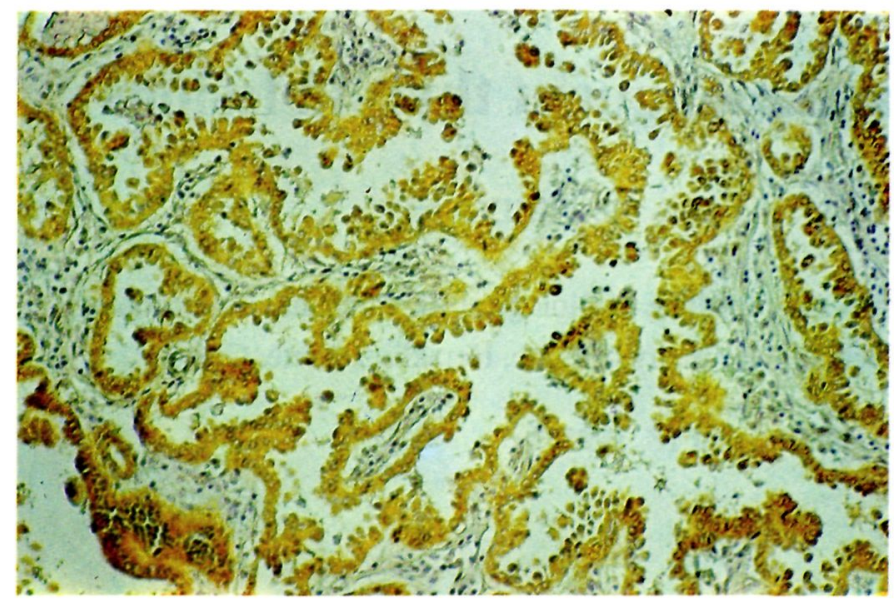

Figure 1. Papillary carcinoma of the thyroid. Intense (++) immunostaining for ras p21 in the cytoplasm of the carcinoma cells (X136).

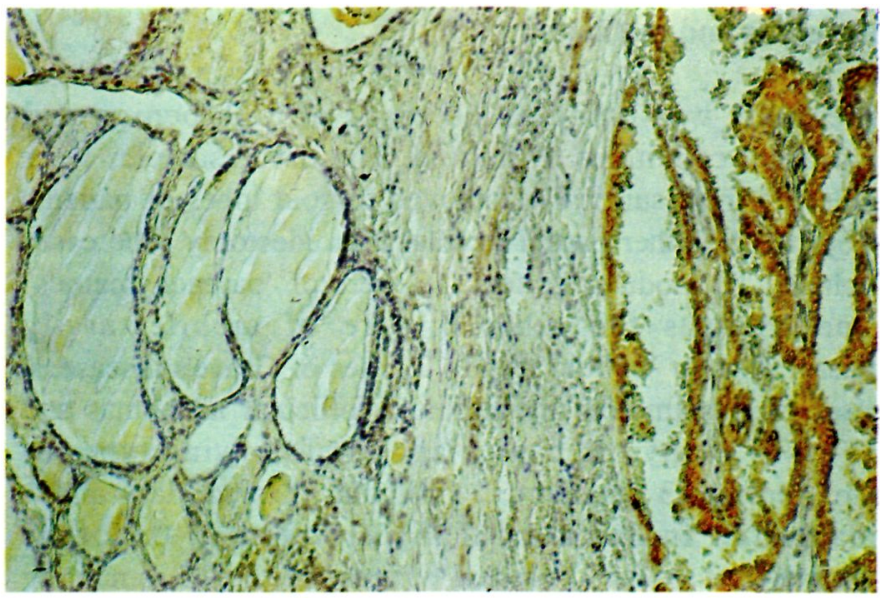

Figure 2. Papillary carcinoma of the thyroid. Intense (++) immunostaining for ras $\mathrm{p} 21$ in the tumor cells and negative immunostaining in macrofollicular areas of the adjacent parenchyma (X136).

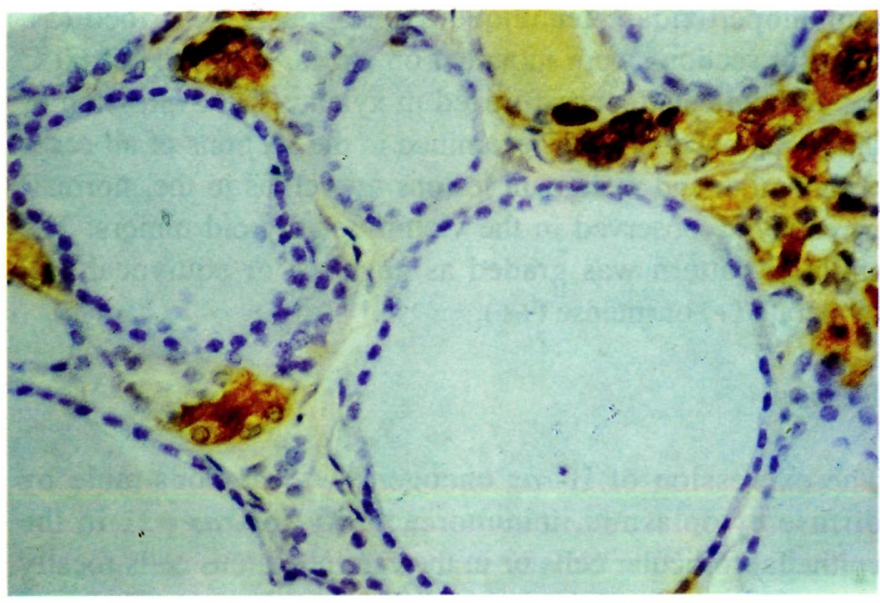

Figure 3. Nodular goiter of the thyroid. Intense (++) immunostaining for ras p21 in microfollicular areas and negative staining in macrofollicular areas (X136).

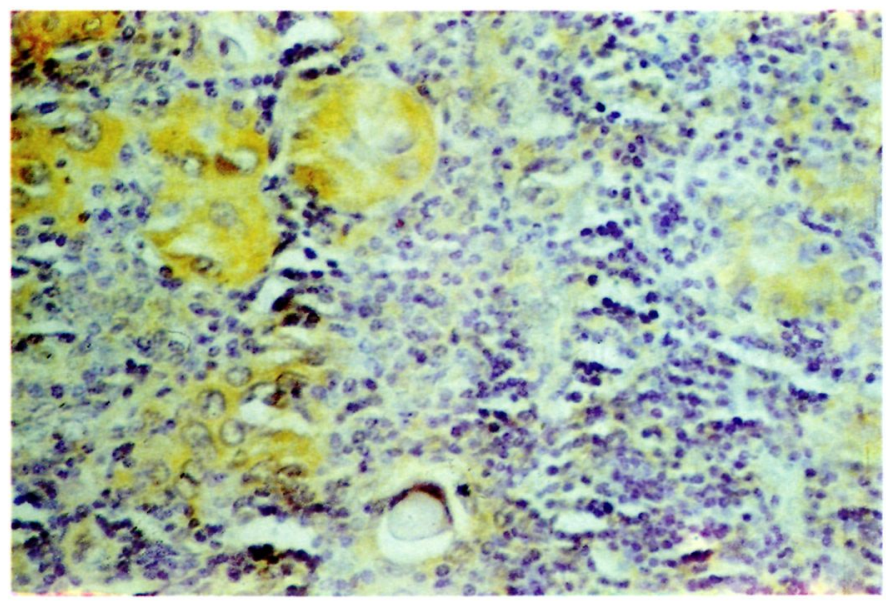

Figure 4. Hashimoto's thyroiditis. Positive (+) immunostaining for ras p21 of the metaplastic oxyphilic follicular cells (X136).

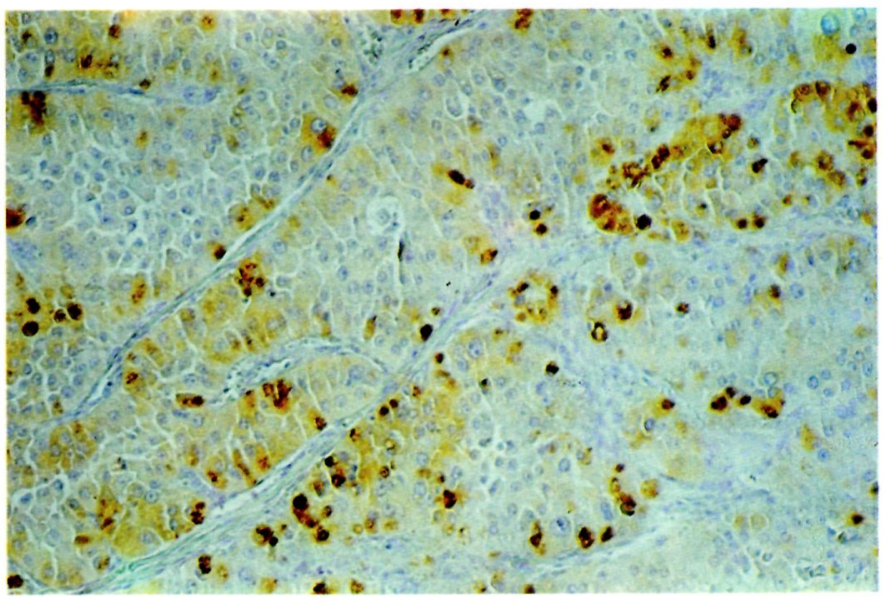

Figure 5. Follicular carcinoma of the thyroid, oxyphilic variant. Focally intense (++) immunostaining for ras p21 (X340).

goiter with focally or diffuse microfollicular ('adenomatous') pattern showed moderate to intense immunoreactivity (Fig. 3). Large epithelial cells in colloid-filled follicles were generally negative in ras expression as was demonstrable in the cases of 'colloid' goiters. Both cases of Crave's disease expressed moderate ras $\mathrm{p} 21$ as well as all cases of Hashimoto's thyroiditis, where the expression was even more intense particularly in cells with oxyphilic metaplasia (Fig. 4). Most of the neoplastic thyroid lesions expressed H-ras oncogene. The benign lesions (adenomas) showed slight or moderate immunoreactivity. Their malignant counterparts (follicular carcinomas) showed immunoreactivity to a slightly lesser extent (Fig. 5). The majority of papillary carcinomas showed strong staining for ras p 21 and in only 2 cases no reaction was demonstrable. No significant differences were found in the staining pattern of the papillary carcinoma related to any histological characteristics, grade of differentiation, or stage of the disease. A summary of the immunohistological analysis of ras p 21 expression in normal, benign and malignant thyroid lesions is shown in Table I. Finally, the ras p21 expression was weak in 
Table I. Immunohistochemical analysis of ras p 21 expression in normal, benign and malignant thyroid lesions.

\begin{tabular}{lll}
\hline $\begin{array}{l}\text { Histological type } \\
\text { of thyroid specimen }\end{array}$ & $\begin{array}{c}\text { Total } \\
\text { no. of cases }\end{array}$ & $\begin{array}{l}\text { Staining intensity } \\
\text { no. of cases (\%) } \\
\end{array}$ \\
& & \pm++
\end{tabular}

\begin{tabular}{lrccc}
\hline Normal adjacent to & & & & \\
papillary carcinoma & 14 & $13(93)$ & $1(7)$ & - \\
follicular carcinoma & 10 & $10(100)$ & - & - \\
medullary carcinoma & 6 & $3(50)$ & $2(35)$ & $1(17)$
\end{tabular}

$\begin{array}{lrccc}\text { Benign } & & & & \\ \text { Nodular goiter } & & & & \\ \quad \text { parenchymatous' } & 10 & 0 & 7(70) & 3(30) \\ \quad \text { 'colloid' } & 6 & 6(100) & - & - \\ \text { Grave's disease } & 2 & - & 2(100) & - \\ \text { Hashimoto's thyroiditis } & 4 & - & 1(25) & 3(75) \\ \text { Follicular adenoma } & 5 & 2(40) & 3(60) & - \\ & & & & \\ \text { Malignant carcinoma } & & & & \\ \quad \text { Papillary } & 23 & 5(22) & 12(52) & 6(26) \\ \quad \text { Follicular. } & 7 & 4(57) & 3(43) & - \\ \quad \text { Medullary } & 8 & 5(62) & 1(13) & 2(25) \\ \quad \text { Anaplastic } & 1 & 1(100) & - & - \\ \end{array}$

medullary carcinomas, while no expression of ras p21 was found in the one case of anaplastic carcinoma (of giant cell type).

\section{Discussion}

Thyroid glands subjected to surgical excision exhibit hyperplastic, inflammatory or neoplastic changes. Thus, the most 'normal' tissue that can be obtained by the pathologist is non-tumorous thyroid parenchyma from glands resected for the presence of a tumor, though the possibility of influence from the tumor tissue cannot be excluded.

The normofollicular thyroid parenchyma adjacent to follicular cell tumors (papillary and follicular carcinomas) which we examined showed only weak expression of rasoncogenes or no expression at all, which is in agreement with reports of others $(6,7)$ whereas the 'normal' thyroid tissue adjacent to medullary carcinoma showed moderate immunoreactivity for ras $\mathrm{p} 21$. This enhanced expression could be the result of epithelial alterations due to unknown peptides secreted by the neuroendocrine tumor cells.

Apparent enhanced expression of the ras-oncogene was demonstrable in most benign proliferative processes which produce goiters e.g. nodular hyperplasia, Crave's disease and Hashimoto's thyroiditis. Cell proliferation seemed to be the main histologic feature related to increased expression of ras-genes since the immunoreactivity was more intense in tissues with prominent hyperplasia, such as Grave's disease and 'adenomatous' areas in nodular hyperplasia. The intense staining in Hashimoto's thyroiditis could be explained by the fact that in many cases of Hashimoto's thyroiditis cell proliferation can be prominent. Therefore, the intensive immunoreactivity for ras p21 of the oxyplilic cells suggests that oxyphilic metaplasia does not represent a degenerative change in Hashimoto's thyroiditis. Our observations are in accordance with previous studies in rat thyroid carcinoma lines which have shown that TSH stimulates proto-oncogene expression (8).

The regulation of ras proto-oncogenes in normal thyroid tissue at different stages of differentiation is still unknown. Although ras oncogene mutations have been associated with thyroid neoplasia (9-13) it remains difficult to assess whether overexpression of ras-oncogenes could cause, or be a consequence of a carcinoma. We observed a significant overexpression of ras-oncogene in well-differentiated follicular-cell carcinoma, and even more intense overexpression in papillary carcinoma. We did not find, however, the elevated apical surface expression of the ras product reported by others (7). It is of interest that, the ras p21 expression in follicular adenomas was slightly more increased when compared to the malignant counterpart (follicular carcinoma). A similar finding has been reported for colon adenomas, where the expression for ras-oncogene was elevated as compared to that found in colon carcinoma $(14,15)$. The similarity in the ras-oncogene expression of cellular hyperplastic nodules, follicular adenomas and follicular carcinomas suggest that ras p21 expression is unable to predict the potential biological behaviour of the examined lesions.

Another interesting finding was the observation that in medullary carcinoma ras p21 was expressed weakly as compared to the follicular cell carcinoma. Medullary carcinoma is a neuroendocrine tumor located in the thyroid gland and is characterized clinically and biochemically by its neurosecretory properties. It has been shown that, when a mutated ras-gene is transfected into a neuroendocrine smallcell lung carcinoma can change its phenotype to that suggesting a non-small cell lung carcinoma without neuroendocrine properties (16). This observation suggests that, ras-oncogene is not related to the neuro-endocrine differentiation.

Long term prognosis of well-differentiated follicular-cell thyroid carcinoma is favourable, modulated by several parameters such as age, histologic characteristics and sex (17). On the contrary, undifferentiated carcinoma or carcinoma with an anaplastic component are very aggressive tumors with rapid progression and fatal outcome.

A relationship has been sought between the overexpression of oncogenes and the prognosis of patients with thyroid cancers by using diverse prognostic indices (18). In our study we have not found any significant differences in the expression of ras oncogene in well-differentiated carcinoma when compared to prognostic parameters, such as size and extension of primary tumor, histological features or presence of metastases.

\section{References}

1. Spandidos DA and Anderson MLM: Oncogenes and oncosuppressor genes: their involvement in cancer. J Pathol 157: 1 $10,1989$.

2. Gonos ES and Spandidos DA: Oncogenes in cellular immortalisation and differentiation. Anticancer Res (In press) 
3. Field JK and Spandidos DA: The role of ras and myc oncogenes in human solid tumors and their relevance in diagnosis and prognosis. Anticancer Res 10: 1-22, 1990.

4. Lemoine NR, Mayall ES, Wyllie FS, Williams ED, Goyns M, Stringer B and Wynford-Thomas D: High frequency of ras oncogene activation in all stages of human thyroid tumorigenesis. Oncogene 4: 159-164, 1989.

5. Papadimitriou K, Yiagnisis M, Tolis G and Spandidos DA: Immunohistochemical analysis of the ras oncogene protein product in human thyroid neoplasms. Anticancer Res 8: 12231227, 1988

6. Johnson TL, Lloyd RV and Thor A: Expression of ras oncogene p21 antigen in normal and proliferative thyroid tissues. Am J Pathol 127: 60-65, 1987.

7. Mizukami Y, Nonomura A, Hashimoto $T$, Terahata $S$, Matsubara F, Mighiguhi T and Noguchi M: Immunohistochemical demonstration of ras p21 oncogene products in normal, benign and malignant human thyroid tissues. Cancer 61: 873-880, 1988.

8. Coletta G, Civafici AM and Vecchio G: Introduction of the cfos oncogene by thyrotropic hormone in rat thyroid cells in culture. Science 233: 458, 1986.

9. Karga H, Lee BK, Vickery A, Thor A, Gez RD and Jameson JL: Ras oncogene mutations in benign and malignant thyroid neoplasms. J Clin Endocrinol Metab 73: 832-836, 1991.

10. Wright PA, Williams ED, Lemoine NR and Wynford-Thomas D: Radiation associated and 'spontaneous' human thyroid carcinomas show a different pattern of ras oncogene mutation. Oncogene 6: 471-473, 1991.
11. Namba H, Rubin SA and Faqin JA: Point mutations of ras oncogenes are an early event in thyroid tumorigenesis. Mol Endocrinol 4: 1474-1479, 1990.

12. Suarez HG, du Villard JA, Saverino M, Cailloce B, Schiumberger M, Tubiana M, Parmentier C and Monier R: Presence of mutations in all three ras genes in human thyroid tumors. Oncogene 5: 565-570, 1990.

13. Kyriakou D, Karkavitsas N, Eliopoulos G and Spandidos DA: Immunohistochemical analysis of the ras p21 oncoprotein in Hashimoto's thyroiditis. Anticancer Res 12: 1189-1194, 1992.

14. Spandidos DA and Kerr IB: Elevated expression of the human ras oncogene family in pre-malignant and malignant tumors of the colorectum. Br J Cancer 49: 681-688, 1984.

15. Williams ARW, Piris J, Spandidos DA and Wyllie AH: Immunohistochemical detection of the ras oncogene p21 product in an experimental tumour and in human colorectal neoplasm. Br J Cancer 52: 687-693, 1985.

16. Mabry M, Nakagawa T, Nelkim B, McDowell E, Gesell M and Eggleston J: v-H-ras oncogene insertion: a model for tumor progression of human small cell lung cancer. Proc Natl Acad Sci USA 85: 6523-6527, 1988.

17. Tubiana $M$, Schlumberger $M$ and Rounger P: Long term results and prognostic factors in patients with differentiated thyroid carcinoma. Cancer 55: 794-799, 1985.

18. Terrier P, Sheng ZM, Schlumberger M, Tubiana M, Caillon B, Travagli JP, Fragn P, Parmetier C and Rion G: Structure and expression of $\mathrm{c}-m y c$ and $\mathrm{c}-\mathrm{fos}$ proto-oncogenes in thyroid carcinomas. Br J Cancer 57: 43-47, 1988. 